\title{
Exploring the nutritional basis of preference and diet selection by sheep
}

\author{
G.P. COSGROVE, G.C. WAGHORN and A.J. PARSONS \\ AgResearch Grasslands, Private Bag 11008, Palmerston North
}

\section{Abstract}

Efficient livestock production from pasture requires an understanding of preference and selection by grazing animals. Selective grazing influences diet not just in the short-term but more importantly, in the long-term through its affect on pasture composition. This paper summarises techniques developed to explore the nutritional basis for preference in complementary indoor and field studies. Indoors, sheep in metabolism crates were offered ryegrass and white clover in separate feed bins. Voluntary intake and eating behaviour were recorded, and following a period of free choice to establish preference, an intra-ruminal infusion of ammonia was given when sheep ate clover. We hypothesised that sheep given additional ammonia with clover would alter selection toward grass as a means of reducing the input of this metabolite from the rumen to the blood stream. When offered a choice, sheep selected a diet comprising $70-85 \%$ clover and $15-30 \%$ grass. Infusion of ammonia did not affect the proportion of grass or clover selected, but it reduced feed intake by about $15 \%$.

In field studies, each of 12 rumen-fistulated sheep was fitted with a harness carrying a remotecontrolled infusion pump and a pack of either water or a urea solution for infusion during grazing. Urea, as a rumen-ammonia precursor, was infused only during periods of eating. Sheep were offered either grass alone or clover alone and infused with urea or water over 4 days to create an association between eating that species and elevated ammonia load. The sheep were then offered a choice between adjacent monocultures of ryegrass and clover for 2 days to test preference and were infused only when the background species was selected. The sheep from the clover background responded to elevated rumen ammonia. They reduced grazing time on both clover alone (275 mins grazing/day when infused with urea vs $325 \mathrm{mins} /$ day for water controls), and when they had a choice between grass and clover (425 vs $490 \mathrm{mins} /$ day for urea infused and control sheep, respectively).

These techniques provide novel opportunities for identifying the roles of plant nutrients in preference and ways these might be manipulated to control diet selection and intake. This paper describes the methods used, and gives preliminary results of trials with clover and grass using ammonia compounds.

Keywords: clover, diet selection, grass, nutritional basis, preference, sheep

\section{Introduction}

Sheep, cattle and goats have a partial preference for white clover over grass (Hughes et al. 1984; Parsons et al. 1994b; Penning et al. 1995a, b). When the constraints to selection are removed by offering a simple choice between two adjacent monocultures and animals are able to eat just one species if they want to, sheep choose a diet comprising 50-70\% white clover (Trifolium repens) and 30-50\% ryegrass (Lolium perenne). Sheep can eat clover faster than they can eat grass indoors (Ulyatt 1984) and outdoors (Penning et al. 1991), and the high nutrient density of white clover suggests this would be the best way to meet energy and nutrient requirements. However sheep show a diurnal pattern of preference for clover, which diminishes as they progressively add grass to their diet throughout the day (Parsons et al. 1994a). Preference also changes with season, and with legume species (Cosgrove et al. 1996). Together, these behaviours suggest diet selection is a highly regulated process. The reason animals choose a mixed diet, with a high proportion of white clover, and with diurnal and seasonal changes in preference, are not understood.

There are practical reasons why it is important to understand the underlying drive for selective grazing from a mixed pasture and why animals prefer mixed diets. Typically, the proportion of clover in mixed pastures in New Zealand is low (Caradus et al. 1996) and this is often attributed to clover being grazed selectively by animals. However, sustained selection for a preferred component is counter-productive to the animal as it reduces the abundance of that component in the diet (Parsons et al. 1991). In addition selective grazing adds to foraging costs, increasing the need to expend energy and increase the duration of grazing to meet nutrient requirements (Parsons et al. 1994b). Unless these costs can be traded off favourably against an improved nutritional value from the selected mixed diet, 
selectivity may again be counter-productive. Creating and maintaining a pasture from which the animal can more easily and sustainably acquire its preferred mixed diet is highly desirable for increasing animal nutrition and productivity. It is therefore essential to understand diet preference and the animals motivation for it to provide the most appropriate diet for our grazing livestock.

There are several nutritional and non-nutritional reasons why an animal might seek a mixed diet with a high proportion of clover. For example, an animal may attempt to regulate the intake of readily degradable protein or the fluxes of metabolic breakdown products of protein digestion, such as ammonia. Too great a release of ammonia may present a challenge to the metabolism of the animal. White clover usually has a higher concentration of protein-nitrogen in the leaves than ryegrass, and this protein is more rapidly released and degraded to ammonia in the rumen (Ulyatt et al. 1988). When sheep or cattle are given a choice between grass and clover, or between high-N and low-N grass they prefer the high-N component (e.g., 70:30, unpublished data), but the intake of the low nitrogen component may serve to regulate the inflow of rumen degradable protein.

By manipulating the supply of nitrogen (and in future soluble carbohydrate) directly to the rumen independently of the plant species identity, and testing the effect of these dietary metabolites on preference, we can begin to determine if there is a nutritional (as opposed to alternative) basis for selection between grass and clover, particularly for the observed preference for a mixed diet.

\section{Methods}

Romney sheep used in these studies were about 1 year old and were prepared with rumen fistulae. Wethers were used for all but one indoor trial, and ewes were used for all outdoor work. Most trials used a degradation product of protein digestion, viz ammonia or urea, infused only when the sheep were eating. Our methodology has evolved over the past 2 years. Initial indoor work was based on infusions of 0.7 and $1.2 \mathrm{~mol}$ of ammonium chloride in $800 \mathrm{ml}$ water per day, but later infusions involved a 1:2 mixture of ammonium chloride and bicarbonate to minimise changes in rumen $\mathrm{pH}$. Outdoor work used urea as a source of rumen ammonia. The amounts of substrate infused were calculated in terms of likely yields from digestion of either grass or clover diets to keep within physiological limits, albeit at extreme of intakes in some instances. The sheep ultimately regulates the amount of material infused into the rumen because infusions only occur when the sheep is eating (indoors) or grazing (outdoors). The longer the time spent eating or grazing, the longer the duration of infusion.

\section{Indoors}

Four sheep (replicates) were used for the indoor experiments. An experiment consisted of a choice of two foods, usually ryegrass and white clover, cut daily and fed at 6-hourly intervals into separate feed bins in front of each caged sheep. The forages were offered for 4 days to establish base-line preference, after which ammonia was infused for 4 days at $0.7 \mathrm{~mol} /$ day with the same food choice but only when one forage was chosen. This was followed by a higher rate of infusion $(1.2 \mathrm{~mol} /$ day) after which a further period of feeding was allowed without infusions to record the return to baseline preference. The response to infusion was determined from the proportions and amounts of the diet selected during the infusion period compared with that selected during the baseline periods. In this way each sheep acted as its own control and each trial lasted approximately 12-16 days.

Sufficient feed was offered to ensure that neither forage was depleted, so that choice was not affected by availability. Feeds were replaced daily, with refusals weighed and dried to determine voluntary intakes. Selection was determined from the total amount of feed consumed from each bin. Rumen liquor was sampled daily to measure $\mathrm{pH}$ and ammonia concentration.

The infusion was only given when sheep ate from one (usually clover) bin. Each bin was fitted with a reflected beam sensor (VF-RMS-3, Sunx Ltd, Japan) that detected movement in and out of each bin. The sensor in the clover bin activated a three-way valve (Goyen 4Q3M3T-NC-SS; Goyen, Australia) to divert infusate into the rumen for the duration of eating from that bin. A variable speed pump (Watson Marlow; Smith and Nephew Watson Marlow, Falmouth, Cornwall U.K.) recycled infusate from the reservoir, through the valve and back to the reservoir, except when the valve was activated. This system was adjusted to continue the infusion for 2 minutes after the sheep withdrew its head from the bin so that movement in and out of the bin (characteristic of some individuals) did not result in a pulsatile flow. The light sensors in both feed bins were linked to a chart-recorder and eating activity was recorded for both forages $24 \mathrm{hrs} /$ day.

Five trials were conducted indoors over 2 years. Comparisons included white clover and grass fed to wethers with infusions of either ammonium chloride or a 1:2 mixture of ammonium chloride and ammonium bicarbonate when clover was consumed. This mixture of ammonium salts was used in later studies after infusion 
with ammonium chloride in early trials resulted in apparent acidosis. Other comparisons using wethers included a choice between two identical grasses with ammonia infused only when the animals ate from one feed bin, and a comparison between the legumes Lotus corniculatus and lucerne (Medicago sativa). The latter evaluation was undertaken to measure effects of both ammonia infusion and of condensed tannins, which limit proteolysis in the rumen, and which could be inactivated by infusion of polyethylene glycol to facilitate the release of ammonia.

\section{Outdoors}

Twelve sheep were allocated to four treatment groups $(n=3)$ in a $2 \times 2$ combination of two background diets (grass or clover) and two infusion treatments, either a metabolically active substrate $(180 \mathrm{~g}$ urea-N/1 as an ammonia precursor) or water (control). Each treatmentgroup of three sheep grazed on a separate plot to avoid group facilitation. Sheep were fed a background diet of either ryegrass alone or white clover alone for 4 days to create an association between eating each feed and elevation of the metabolite (rumen ammonia). They received infusion $(1 \mathrm{ml} / \mathrm{min})$ only when eating. It was intended that an association between the infusion and the feed on offer would be formed within 4 days, after which they were given a choice of two feeds. One of the two feeds was the same as the background, and sheep received the infusion only when eating the background feed (i.e., grass background sheep were infused only when eating grass and clover background sheep were infused only when eating clover). This choice was offered for 2 days. Replication was achieved by repeating these runs (background plus choice) three times, with sheep re-randomised among treatments for each replicate.

Each group of sheep was allocated a plot of 0.2 ha for the background period, and a similar sized plot comprised of 0.1 ha of both grass and clover for the choice period. Plots were mowed at the start of each run to ensure sward surface height was similar for all plots. Pluck samples of herbage, representative of the diet, were taken from each plot twice during each period to determine the concentration of nitrogen in the feed eaten.

In addition to the peristaltic infusion pump (SIRO pump, CSIRO, Australia) and pack of infusate, the sheep also carried a radio-controlled receiver so that the pumps could be operated from a remote site without disturbance. Sheep were bought into yards between $10 \mathrm{am}$ and $12 \mathrm{am}$ to replace infusate packs and change batteries etc. This time was chosen to coincide with a period when they were not usually grazing, so as to minimise the disruption to normal behaviour. Sheep were observed continuously during daylight hours and the predominant activity (grazing, or any other nongrazing activity) recorded at 5-minute intervals. At the end of each 5-minute period a decision was made, based on predominant activity during that interval, to either switch the pump if activity had changed or to retain at current setting. This protocol resulted in a lag of between 3 and 7 minutes from the sheep starting or stopping grazing until the pump was switched accordingly. Total time spent grazing was calculated from the sum of the 5-minute observations. Relative preference was expressed as the proportion of total grazing time spent on each of the alternatives.

\section{Results}

\section{Indoors}

When ammonium chloride was infused into wethers at $0.7 \mathrm{~mol} /$ day in the initial experiment, two of the four sheep altered their choice from 75:25 to $32: 68$ clover:grass. This change was achieved by initially reducing clover intake and then by increasing grass intake. When the infusion ceased, clover intake had been reduced to $25 \%$ of pre-infusion level and grass intake increased to $70 \%$ above pre-infusion level. Four days after the infusion ceased, dry matter intake had increased to pre-infusion level (1600 g/day) with grass accounting for $27 \%$ of intake. Of the other two sheep, one reduced intake by $18 \%$ in response to infusion without altering choice and the other was removed from the trial after losing its appetite. Although rumen $\mathrm{pH}$ was not measured in this trial, the absence of normal rumen function in the sheep removed from the trial suggests that the alteration in choice described above was affected by acidosis. Subsequent trials have used a mixture of ammonium chloride and bicarbonate salts and ruminal $\mathrm{pH}$ has been monitored daily in all experiments.

In a subsequent experiment, sheep were offered grass in each bin, but infused with $0.7 \mathrm{~mol} /$ day only when they selected from one bin. They were unable to associate the infusion with the choice of feed bin. They selected $48.6 \pm 3.07 \%$ (SD) from the right-side bin before infusion and $46.7 \pm 8.27 \%$ from the same bin during infusion $(\mathrm{P}=0.33)$. The only response to infusion was to reduce dry matter intake from $1500 \mathrm{~g} /$ day to $1100 \mathrm{~g}$ /day during infusion. Intake increased to $1340 \mathrm{~g}$ /day when infusion ceased.

Results from a dietary choice between grass and clover offered to wethers receiving infusion of mixed ammonium salts in association with eating clover is given in Table 1. The clover had $46 \mathrm{~g} \mathrm{~N} / \mathrm{kg} \mathrm{DM}$, and although the grass remained leafy throughout the trial the nitrogen concentration declined from 32 to $25 \mathrm{~g} \mathrm{~N} /$ 
Table 1 Voluntary intake (dry matter, DM), diet choice and ruminal pH of four wethers offered a choice of grass or clover with and without an intraruminal infusion of ammonia salts when clover was selected. Each period was 4 days duration; data are means with standard deviations $(n=4)$.

\begin{tabular}{|c|c|c|c|c|c|c|c|c|}
\hline & -- Prei & ion -- & $--0.7 \mathrm{~m}$ & $\mathrm{JH}_{3} / \mathrm{d}--$ & $--1.2 \mathrm{mc}$ & $1_{3} /$ day -- & -- Post & sion -- \\
\hline & Mean & SD & Mean & SD & Mean & $S D$ & Mean & SD \\
\hline DM intake (g/day) & 1440 & 294 & 1371 & 230 & 1379 & 210 & 1492 & 221 \\
\hline Grass intake (\% DM) & 43 & 8.3 & 27 & 8.3 & 23 & 9.1 & 20 & 10.9 \\
\hline Eating times (min/day) & & & & & & & & \\
\hline Clover & 171 & 35.9 & 191 & 42.0 & 203 & 39.9 & 212 & 36.4 \\
\hline Grass & 145 & 28.6 & 88 & 21.6 & 90 & 35.1 & 81 & 38.2 \\
\hline Eating rate $(\mathrm{g} / \mathrm{min})$ & & & & & & & & \\
\hline Clover & 4.8 & 1.18 & 5.3 & 0.94 & 5.3 & 1.44 & 5.7 & 1.40 \\
\hline Grass & 4.4 & 0.82 & 4.2 & 0.96 & 3.7 & 1.15 & 4.0 & 0.95 \\
\hline Rumen $\mathrm{pH}$ & 6.2 & 0.14 & 6.4 & 0.18 & 6.5 & 0.24 & 6.3 & 0.21 \\
\hline
\end{tabular}

Table 2 Effect of urea infused into the rumen on the time spent grazing (minutes/day) by sheep on grass or clover monocultures (background period) and then offered a choice between grass and clover (choice period).

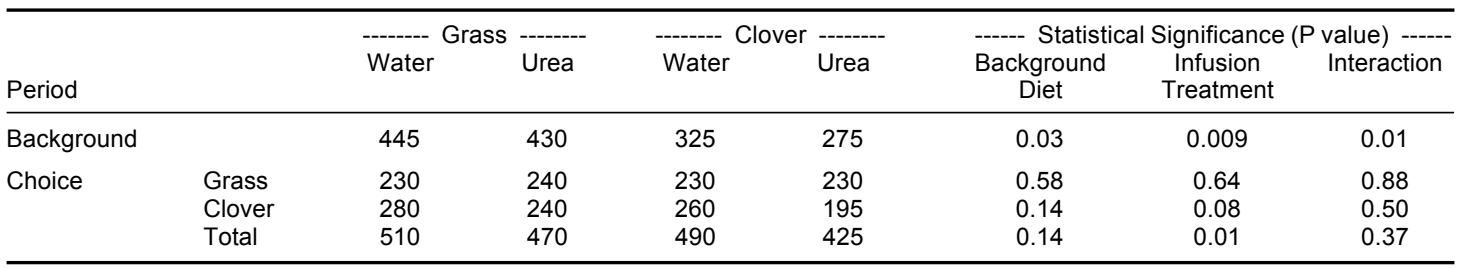

kg DM over 16 days. The sheep (45 kg liveweight) consumed $1020 \mathrm{~g}$ clover and $410 \mathrm{~g}$ grass dry matter daily. Infusion of ammonia salts did not affect the proportion of clover selected, but daily intake was reduced by about $6 \%$ during infusion $(\mathrm{P}=0.11)$. Infusion did not affect the rate of dry matter intake or rumen $\mathrm{pH}(\mathrm{P}=0.08)$.

\section{Outdoors}

Grazing Time: The time spent grazing each day for sheep offered grass or clover monocultures during the background period, and when offered a choice is shown in Table 2. During the background period, sheep offered clover spent less time grazing than those offered grass $(\mathrm{P}<0.05)$. There was a significant $(\mathrm{P}<0.01)$ background species $\times$ infusion treatment interaction. Infusing sheep with urea caused a larger reduction in grazing time for those offered clover (reduced by 50 minutes compared with their water controls) than for those offered grass (reduced by 15 minutes compared with their water controls). When offered a choice between grass and clover, background diet had little effect on grazing time. Time spent grazing grass was similar for all treatment groups (230 minutes), but those infused with urea spent less time grazing on clover $(\mathrm{P}=0.08)$, especially those from the clover background diet although the interaction was not significant $(\mathrm{P}=0.5)$.

Nitrogen Intake: The nitrogen concentration in grass was $26 \mathrm{~g} / \mathrm{kg}$ dry matter and $58 \mathrm{~g} / \mathrm{kg}$ in clover. The daily ammonia-nitrogen load in the rumen, a function of grazing time, nitrogen concentration in the diet and that received via infusion (and a calculated value for proteolysis for grass and clover), is shown in Table 3. During the background period, sheep grazing clover received higher ruminal nitrogen input than those grazing grass. However for sheep grazing clover, the additional load imposed by infusion was lower than that for the sheep grazing grass, because they spent 
less time grazing. When given a choice between grass and clover, the ammonia input increased for those from the grass background because they continued to receive infusion while eating grass, and they received additional ammonia from the clover added to their diet. Infused sheep from the clover background had a reduced ammonia load when given a choice, because they added grass (low ammonia release) to their diet.

\section{Discussion}

\section{Technique development}

An important aspect of these trials has been the development of methods to alter metabolite load directly in association with eating, and independently of plant species. Indoors, this was achieved with a light sensor to detect a specific food choice and infuse accordingly. Outdoors, observation and a remote control switch was used to achieve the same without disturbance to the animal. Grazing animals consume food throughout a day in a series of meals with distinct start and endpoints (Rook \& Penning 1991), related in part to digesta and metabolite load. By elevating a metabolite in synchrony with a meal, an animal may be able to associate the metabolic consequences directly with eating, and if it is important, can deal with it by regulating the time spent grazing. At this early stage, we are testing the role of major digestive metabolites in the link between nutrition and selection. In future we will simulate the variation in plant nutrient composition that might be created by plant breeding (for example, increased or decreased soluble carbohydrate) and examine the consequence for preference and selection by the animal, and for pasture composition.

The results presented here illustrate the challenges arising from this type of experimentation. An indoor facility allows good measurements of voluntary intake and behaviour $24 \mathrm{~h} /$ day, but the feed on offer may differ in quality and other physical attributes from that selected by sheep during grazing. Another problem associated with the indoor feeding facility is that sheep are able to rapidly alternate between feed bins, typically eating one choice for only minutes at a time. This rapid switching between foods may not allow sufficient time for a metabolic association to be made with a particular food choice. In contrast, the grazing trials used spatially separate plots of grass and clover, so sheep tended to graze for longer periods, or even complete meals, on one species before walking to the adjacent plot. This spatial separation of contrasting forages facilitated infusing directly with a particular food choice and allowed more time for sheep to develop an association between eating that food and the resulting metabolite load, and then to make a particular diet choice.

\section{Towards a nutritional basis to selection}

These results show that sheep can detect an increased ammonia load and will respond to this by regulating some aspects of eating and grazing behaviour. Sheep held indoors reduced dry matter intake and outdoors, the shorter time spent grazing is indicative of lower intake. Outdoors, the response to elevated rumen ammonia was largest for sheep offered clover, itself high in rumen-degradable protein, during the background period. However, the reduction in grazing time, and therefore the reduction in the intake of nitrogen of dietary origin, did not fully compensate for the extra ammonia- $\mathrm{N}$ from infusion. When given a choice between grass and clover, sheep receiving urea in association with clover spent less time grazing clover compared to other treatments, but they did not increase grazing time on grass to maintain dry matter intake. Grass provided a lower daily ammonia load to the rumen than clover because of its lower nitrogen concentration and the slower rate of nitrogen release. We hypothesised that when given the opportunity, sheep being infused with ammonia might increase their preference for the alternative species (or decrease preference for the species associated with the infusion) to deal with the excess ammonia. Sheep from the clover background did not increase preference for grass as expected. However, because of their lower grazing time on clover, these sheep had a higher proportion of grass in their diet than the other treatment groups. For this group, offering a choice allowed them to reduce the daily rumen-ammonia load to a level below that received during the background period, and possibly below a critical threshold of sensitivity to daily ammonia load or rate of release of ammonia in the rumen. These preliminary results show that a high input of ammonia nitrogen affects intake, and that sheep control their nutrient intake. A nutritional basis to preference and selection, such as rumen ammonia load, remains to be elucidated.

The lower grazing time of sheep offered clover compared with those offered grass is similar to that recorded previously (Lancashire \& Keogh, 1966; Penning et al. 1991). Infusing additional nitrogen to each diet increased this difference between grass and clover. When sheep were offered a choice, they spent approximately equal amounts of time grazing each species. However, rather than the total grazing time being intermediate between the extremes of the monoculture diets as might be expected, it was higher for all treatments, even for sheep from the grass background. If the higher grazing time translates directly to higher daily intake, then this alone suggests a benefit to sheep of allowing them to eat a mixed diet from spatially separate monocultures. More profoundly, if 
sheep combine the high intake rate grazing clover (Penning et al. 1991; authors' unpublished data) with the longer grazing time recorded for the mixed diet, then the benefit to daily intake is potentially large.

\section{ACKNOWLEDGEMENTS}

The contributions from Craig Anderson, John Brock and Jocelyn Tilbrook during the planning and conduct of these trials are greatly appreciated.

\section{REFERENCES}

Caradus, J.R.; Woodfield, D.R.; Stewart, A.V. 1996. Overview and vision for white clover. Agronomy Society of New Zealand Special Publication No.11/ Grassland Research and Practice Series No. 6: 16.

Cosgrove, G.P.; Anderson, C.B.; Fletcher, R.H. 1996. Do cattle exhibit a preference for white clover? Agronomy Society of New Zealand Special Publication No.11/Grassland Research and Practice Series No. 6: 83-86.

Hughes, T.P.; Sykes, A.R.; Poppi, D.P. 1984. Diet selection of young ruminants in late spring. Proceedings of the New Zealand Society of Animal Production 44: 109-112.

Lancashire, J.A.; Keogh, R.G. 1966. Some aspects of the behaviour of grazing sheep. Proceedings of the New Zealand Society of Animal Production 26: 22 35.

Parsons, A.J.; Harvey, A.; Johnson, I.R. 1991. Plantanimal interactions in a continuously grazed mixture. II. The role of differences in the physiology of plant growth and of selective grazing on the performance and stability of species in a mixture. Journal of applied ecology 28: 635-658.
Parsons, A.J.; Newman, J.A.; Penning, P.D.; Harvey, A.; Orr, R.J. 1994a. Diet preference of sheep: effects of recent diet, physiological state and species abundance. Journal of animal science 63: 465-478.

Parsons, A.J.; Thornley, J.H.M.; Newman, J.; Penning. P.D. 1994b. A mechanistic model of some physical determinants of intake rate and diet selection in a two-species temperate grassland sward. Functional ecology 8: 187-204.

Penning, P.D.; Rook, A.J.; Orr, R.J. 1991. Patterns of ingestive behaviour of sheep continuously stocked on monocultures of ryegrass or white clover. Applied animal behaviour science 31: 237-250.

Penning, P.D.; Newman, J.A.; Parsons, A.J.; Harvey, A.; Orr, R.J. 1995a. The preference of adult sheep and goats grazing ryegrass and white clover. Proceedings of the $4^{\text {th }}$ International symposium on the nutrition of herbivores. Annales de Zootechnie 44 Suppl.: 113.

Penning, P.D.; Parsons, A.J.; Orr, R.J.; Harvey, A.; Yarrow, N. 1995b. Dietary preferences of heifers for grass or clover, with and without rumensin slowrelease anti-bloat boluses. Animal science 60: 550A.

Rook, A.J.; Penning, P.D. 1991. Synchronisation of eating, ruminating and idling activity by grazing sheep. Applied animal behaviour science 32:157166.

Ulyatt, M.J. 1984. Pasture composition and animal production. pp. 195-203. In: Ruminant physiology concepts and consequences. Eds. Baker, S.K.; Gawthorne, J.M.; Mackintosh, J.B.; Purser, D.B. Nedlands, University of Western Australia.

Ulyatt, M.J.; Thomson, D.J.; Beever, D.E.; Evans, R.T.; Haines, M.J. 1988. The digestion of perennial ryegrass (Lolium perenne L. cv. Melle) and white clover (Trifolium repens L. cv. Blanca) by grazing cattle. British journal of nutrition 60: 137-149. 